\title{
ETIOLOGY AND OUTCOME OF CULTURE PROVEN BACTERIAL MENINGITIS IN CHILDREN 6 TO 24 MONTHS OF AGE.
}

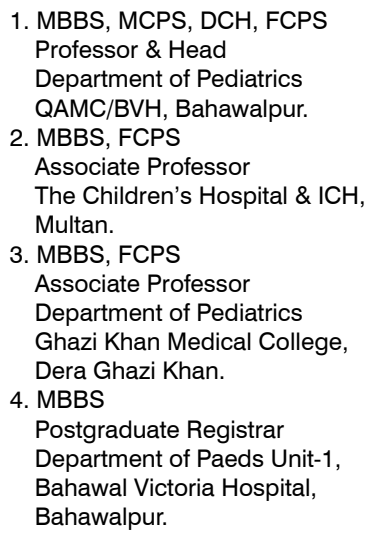

Correspondence Address:

Dr. Muhammad Amin Department of Pediatrics QAMC/BVH, Bahawalpur. dr.aminshbwp@gmail.com

Article received on: $15 / 12 / 2018$

Accepted for publication: 25/04/2019

Received after proof reading: 28/08/2019

\begin{abstract}
Muhammad Amin', Asim Khurshid ${ }^{2}$, Mukhtar Ahmad ${ }^{3}$, Zunaira Javed ${ }^{4}$
ABSTRACT... Introduction: Pediatric bacterial meningitis is a life-threatening illness that results from bacterial infection of the meninges and leaves some survivors with significant sequelae. More than $2 / 3$ cases of meningitis occur in the $1^{\text {st }} 2$ years of life, owing to decreased immunity and high vascularity of the brain. This study was conducted to determine the frequency of hemophilus influenzae type b, streptococcus pneumonia and neisseria meningitidis and outcome in culture proven meningitis in children 6 months to 24 months. Study Design: Case series. Setting: Paeds Unit 1, Bahawal Victoria Hospital, Bahawalpur and Paeds Unit of District Headquarter (DHQ) Teaching Hospital, Dera Ghazi Khan. Period: $1^{\text {st }}$ April 2017 to $30^{\text {th }}$ September 2018. Material and Methods: A total of 220 children (110 from each center) of either sex with culture proven meningitis, aged 6 months to 24 months, were included in the study. Demographics, duration of fever, history of seizures, weight of child, vaccination status and bacteria isolated from CSF and outcome were analyzed. The outcome in the form of mortality was noted during the first 10 days of hospital stay. Results: Amongst a total of 220 children, 123 (55.9\%) were male. There were $130(59.1 \%)$ children who were less than or equal to 1 year of age. There were 154 $(70.0 \%)$ children who were having a weight of 7 to $10 \mathrm{~kg}$. Vaccination status was, $111(50.5 \%)$ were fully vaccinated, $59(26.8 \%)$ partially vaccinated and $50(22.7 \%)$ not vaccinated. Duration of fever was, $141(64.1 \%)$ had fever for more than 5 days. There were 139 (63.2\%) children who had a history of seizures. Streptococcus pneumonia was the commonest bacteria found in 110 (50\%) children followed by neisseria meningitides 53 (24.1\%), H. Influenza 37 (16.8\%). Overall mortality was noted in $34(15.5 \%)$ children. Conclusion: In children with bacterial meningitis, mortality was high and most common bacteria were found to be s.pneumoniae followed by neisseria meningitidis and $h$.influenzae. Awareness about the empiric and directed antimicrobial therapy will help to lower the burden of morbidity and mortality related to bacterial meningitis.
\end{abstract}

Key words: Bacterial Meningitis, Streptococcus Pneumoniae, H. Influenza, Mortality.

Article Citation: Amin M, Khurshid A, Ahmad M, Javed Z. Etiology and outcome of culture proven bacterial meningitis in children 6 to 24 months of age. Professional Med J 2019; 26(9):1451-1456. DOI: 10.29309/TPMJ/2019.26.09.2562

\section{INTRODUCTION}

Pediatric bacterial meningitis is a life-threatening illness that results from bacterial infection of the meninges and leaves some survivors with significant sequelae. More than $2 / 3$ cases of meningitis occur in the $1^{\text {st }} 2$ years of life, owing to decreased immunity and high vascularity of the

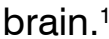

The three most common bacteria among the age group of 2 months to 24 months in the descending order of frequency were hemophilus influenza type b, streptococcus pneumonia and Neisseria meningitides before the introduction of conjugated Hemophilus influenza and pneumococcal vaccination in routine immunization program. The introduction of these vaccinations not only reduced the mortality but also changed the etiology of bacterial meningitis. ${ }^{2}$ So, now in vaccinated children, the most common organism in the descending order of frequency are streptococcus pneumonia, neisseria meningitides while the incidence of meningitis due to hemophilus influenza type $b$ has dramatically decreased. ${ }^{3}$ The study done by Chinchankar $\mathrm{N}$ et al in $2002^{4}$ before the introduction of hemophilus influenza type b, streptococcus pneumonia routine vaccination showed streptococcus pneumonia 39\% hemophilus influenza type b $26 \%$ and others $35 \%$, and mortality in $31.5 \%$ of cases. 
The study done by Levy $C$ et al in $2014^{5}$ showed mortality $10.6 \%$ after the introduction of routine vaccination. The study done by Kuti BP et al in $2015^{6}$ in Nigeria, where vaccination is very poor showed commonest bacteria $\mathrm{H}$. influenza type $\mathrm{b}$ and S. pneumonia while mortality was $27.2 \%$. The studies done in various parts of Pakistan showed highly variable mortality from study to study ranging from $1.67-34 \% .{ }^{7-10}$

The routine vaccination in Pakistan especially in our area is very poor and meningitis is a common problem with a highly variable mortality in other parts of Pakistan with no local data is available. Moreover, the search done on PUBMED, PAKMEDINET and MEDLIP showed that very little national but no local data available about the etiology of bacterial meningitis below the 2 years of age after introduction of $\mathrm{H}$. influenza type $\mathrm{b}$ and S. pneumonia. So, this study was planned to determine the frequency of hemophilus influenza type b, streptococcus pneumonia and neisseria meningitidis and outcome in culture proven meningitis in children 6 months to 24 months. This study will help us in decreasing the morbidity and mortality due to the meningitis in the community.

\section{MATERIAL AND METHODS}

This was a case series, conducted at Paeds Unit 1, Bahawal Victoria Hospital, Bahawalpur and Paeds Unit of District Headquarter (DHQ) Teaching Hospital, Dera Ghazi Khan from $1^{\text {st }}$ April 2017 to $30^{\text {th }}$ September 2018.

Anticipated frequency of H.influenzae in meningitis was $17.24 \%$ from a study conducted at Hyderabad, Pakistan. ${ }^{9}$ Absolute precision was taken as $5 \%$ and the design affect was taken as 1 . The sample size was calculated as 220 through sample size software available at http://www. openepi.com/samplesize.

A total number of 220 children (110 from each center) of either sex with culture proven meningitis, having 6 months to 24 months of age were considered for this study using non probability, consecutive sampling. Children with unknown vaccination status due to unavailability of vaccination card, whose parents/guardians did not give consent to enter the study or with meningitis following head injury or meningocele / myelomeningocele were excluded from this study.

All children coming either from outpatient department or through emergency were included in the study after scrutinizing the inclusion and exclusion criteria. The verbal consent was taken from parents / guardians. Proper history was taken from the mother / guardian. Demographic and clinical data was entered on a specifically designed proforma. Demographic and clinical data included name, age, gender, duration of fever $\left(>38^{\circ} \mathrm{C}\right)$, history of seizure/seizures (defined as uncontrollable shaking of body that is rapid and rhythmic, with the muscle contract and relax repeatedly) developing during hospital stay, weight of child, vaccination status and bacteria isolated from CSF and outcome of the patient. A child who had missed any of the vaccines given as per EPI schedule till the time he appeared in this study was classified as partially immunized (likewise who had completed all the vaccines were labeled as fully vaccinated, and with no vaccination history was labeled as no vaccination status).

Culture proven meningitis was confirmed as any bacterial growth of $h$. influenza type $b$ (non hemolytic, opaque cream-to-gray colonies on culture media), streptococcus pneumonia (small, grey, moist, colonies producing zone of green on culture media) and Neisseria meningitides (grayish, non-hemolytic, round, convex, smooth, moist, glistening colonies with a clearly defined edge on culture media) after inoculation of CSF on blood agar and chocolate agar for 48 hours. ${ }^{11}$ Central Laboratories of Pathology Departments of the concerned institutions were used for all the laboratory investigations. Seizure was labeled as uncontrollable shaking of body that is rapid and rhythmic, with the muscle contract and relax repeatedly. Levetiracetam and phenobarbital were used as anticonvulsants. All cases were given IV antibiotics (vancomycin $60 \mathrm{mg} / \mathrm{kg} /$ day given every 8 hourly and Ceftriaxone 100mg/ $\mathrm{kg} /$ day given 12 hourly) for a period of 10 days. Injection dexamethasone was also given IV 
$0.2 \mathrm{mg} / \mathrm{kg} /$ dose 8 hourly for 2 days starting with the $1^{\text {st }}$ dose of antibiotics. The outcome was measured in terms of death (labeled as absence of spontaneous or induced movement of the body with no respiration and flat electrocardiogram) of the child during the first 10 days of hospital stay.

SPSS Version 18 was used for statistical data analysis. Mean and standard deviations for age, weight and duration of fever were calculated. The frequency and percentage were calculated for $h$. influenza type b, streptococcus pneumonia and neisseria meningitidis, presence of seizures, vaccination status and mortality. Effect modifiers like age, weight, duration of fever, presence of seizures an vaccination status were controlled through stratification. Post stratification chi square test was applied and $p$ value less than or equal to 0.05 was taken as significant.

\section{RESULTS}

Amongst a total of 220 children, 123 (55.9\%) were male and 97 (44.1\%) female. There were 130 $(59.1 \%)$ children who were less than or equal to 1 year of age while 90 (40.9\%) over 1 year. Mean age amongst children was 13.38 months with a standard deviation of 5.9 months. There were $62(28.2 \%)$ children who were having weight of less than or equal to $6 \mathrm{~kg}, 154(70.0 \%)$ having 7 to $10 \mathrm{~kg}$ and $4(1.8 \%)$ over $10 \mathrm{~kg}$. Mean Weight was $7.26 \mathrm{~kg}$ with a standard deviationof $1.8 \mathrm{~kg}$. As far as vaccination status was concerned, 111 $(50.5 \%)$ were fully vaccinated, $59(26.8 \%)$ partially vaccinated and 50 (22.7\%) not vaccinated.

Duration of fever was, 79 (25.9\%) having fever from five or less days whereas 141 (64.1\%) for more than 5 days. There were 139 (63.2\%) children who had a history of seizures.

Streptococcus pneumonia was the commonest bacteria found in 110 (50\%) children followed by neisseria meningitides $53(24.1 \%), \mathrm{H}$. Influenza $37(16.8 \%)$ whereas $20(9.1 \%)$ children were found having other bacteria (citrobacter in 4 cases, pseudomonas in 7, klebsiella in 9). Overall mortality was noted in 34 (15.5\%) children. of outcome, $p$ value turned out to be $>0.05$ that proved statistical insignificance for all variables in terms of outcome in children with bacterial meningitis.

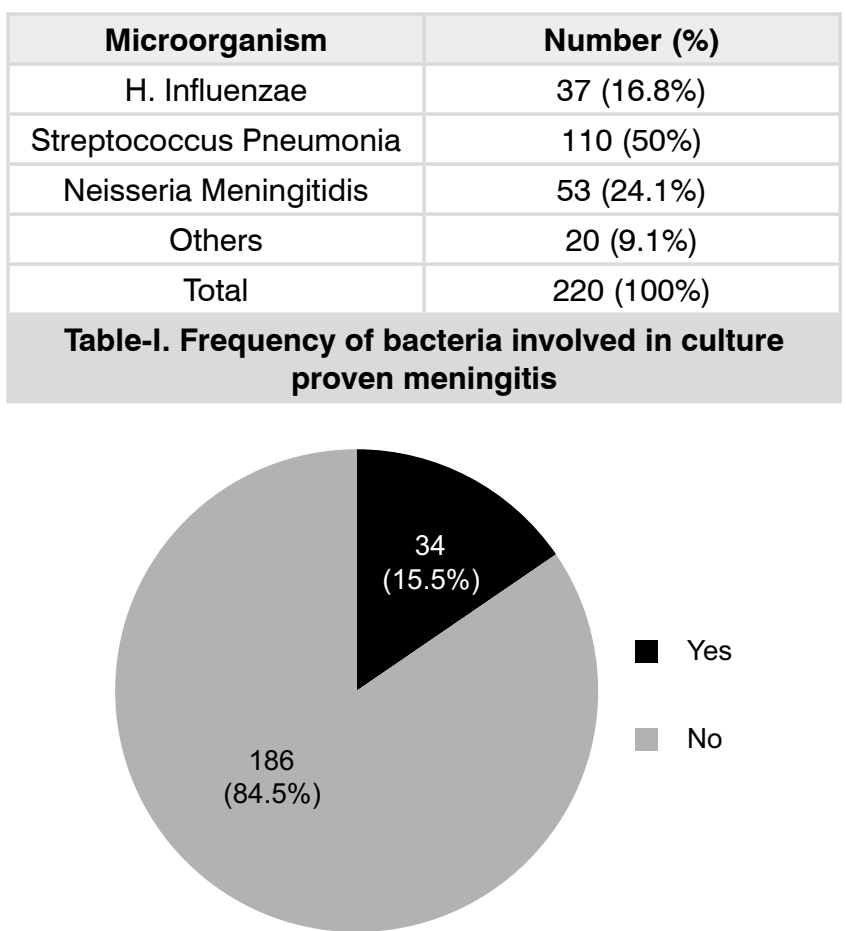

Figure-1. Mortality amongst children

\section{DISCUSSION}

Bacterial meningitis contributes considerably to children morbidity and mortality. ${ }^{12}$ In the present study, more male children (55.9\%) got enrolled as compared to females. This has been found earlier as well that males are affected more as compared to females. ${ }^{13}$

Age has been an important contributing factor in terms of contribution to incidence and mortality related to bacterial meningitis. The incidence of bacterial meningitis is very age specific as it is found more among newborn infants and elderly. The attack rates for newborn are around 400 cases per 100,000 while this is reduced to only 1-2 per 100,000 in adults. We found that 130 $(59.1 \%)$ children were having age less than or equal to 1 year. ${ }^{14}$ 


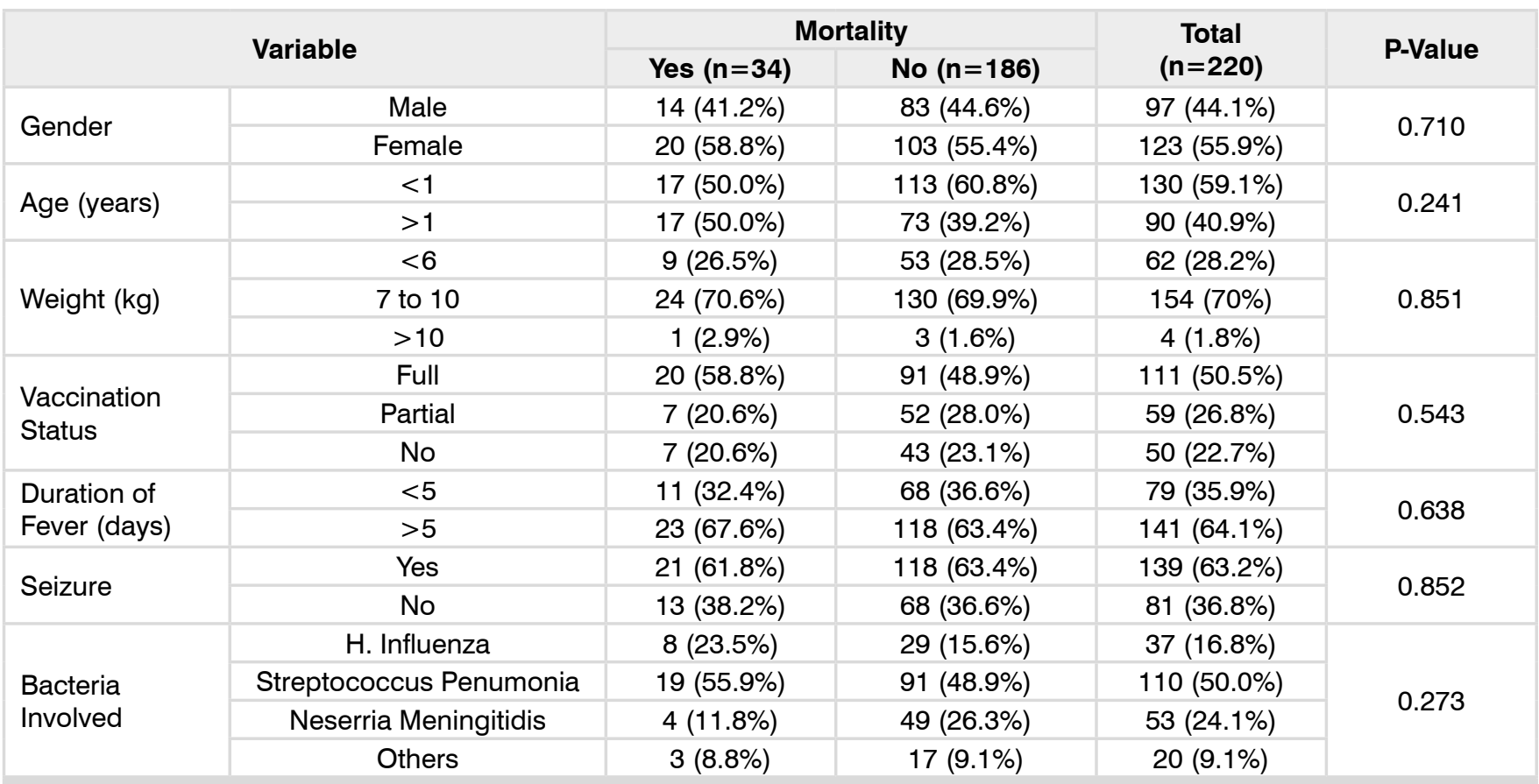

Table-Il. Mortality and age amongst children

In the present study, 62 (28.2\%) children who were having weight of less than or equal to $6 \mathrm{~kg}$, $154(70.0 \%)$ having 7 to $10 \mathrm{~kg}$ and $4(1.8 \%)$ over $10 \mathrm{~kg}$. Mean Weight was $7.26 \mathrm{~kg}$ with a standard deviation of $1.8 \mathrm{~kg}$. It has been found earlier that $51 \%$ of the cases were noted to be malnourished and belonged to low socio-economic class who were related with higher mortality rates. ${ }^{9}$ Malnourished newborns have high rates of infections and have high mortality rates and this fact has been recorded in various studies conducted around the world. ${ }^{15,16}$

Vaccination status in this study showed that $50(22.7 \%)$ were not vaccinated. Children with meningitis must be carefully handled. Management involves fast and appropriate diagnosis, antimicrobial therapy, adjunctive and supportive therapy, chemoprophylaxis for contacts and vaccination for prevention. Currently available vaccines target the most common bacterial causes of meningitis: $S$ pneumonia, $H$. influenza. These microorganisms are largely human pathogen, contain a polysaccharide capsule as the main virulence determinant of and that capsular types associated with meningitis are only a small subset of those that colonize the nasopharynx, these similarities are important for vaccine development. ${ }^{17}$

In our study, most common bacteria was found as streptococcus pneumonia, $110(50 \%)$ children followed by neisseria meningitides $53(24.1 \%), \mathrm{H}$. Influenza 37 (16.8\%) whereas 20 (9.1\%) children were found having other bacteria. Overall mortality was noted in 34 (15.5\%) children which are quite similar to other findings. S. Pneumoniae was the commonest bacteria (55.9\%) found in children who died followed by $\mathrm{H}$. Influenzae (23.5\%) in our study. Mortality in children has been found to be associated commonly with E.coli in neonatal age but we conducted this study in children having age 6-24 months. A local study conducted by Kakkar et al found s.pneumoniae as the commonest cause of mortality in bacterial meningitis followed by H.influenzae. ${ }^{9}$ We found a similar pattern but age did not contribute significantly when compared for mortality. Mortality rate of $14 \%$ by Azubuick JC, ${ }^{18}$ in 1990 and $20 \%$ by Louvis $\mathrm{J}$ et $\mathrm{al}^{19}$ in 1991 was found. In 1974, Bulter lan $\mathrm{J}$ et $\mathrm{al}^{20}$ found $65 \%$ cases of gram negative microorganisms associated with mortality in neonatal bacterial meningitis while Akbani $\mathrm{Y}^{21} 27.3 \%$ and Tajj MM et al ${ }^{22} 28 \%$ in 1993. In an earlier study, ${ }^{12}$ s.pneumoniae was responsible for $30 \%$ of mortality rate in children while Akbani $\mathrm{Y}$ et al, ${ }^{21}$ 
1998 showed $66.7 \%$ mortality in males and $33.3 \%$ in females, it may be due to high incidence of meningitis in males.

Duration of illness before admission to hospital appear to be a contributing factor to mortality in bacterial meningitis. ${ }^{9}$ In present study, duration of fever was not significantly associated with mortality but 79 (25.9\%) children had fever from five or less days whereas other 141 (64.1\%) had fever for more than 5 days. It has been revealed in the past that prolonged duration of illness prior to the admission lead to delay in diagnosis an initiation of effective and adequate management of the disease.

In terms of limitations to this current study, we were unable to acquire further information such as short or long-term follow-up to assess the long-term sequelae of meningitis in our patients. Secondly, this study lacked information on antibiotic use before the hospital admission and, there are no details regarding bacterial resistance.

\section{CONCLUSION}

In children with bacterial meningitis, mortality was high and most common bacteria were found to be s.pneumoniae followed by neisseria meningitidis and h.influenzae. Awareness about the empiric and directed antimicrobial therapy will help to lower the burden of morbidity and mortality related to bacterial meningitis.

\section{Copyright(C) 25 Apr, 2019.}

\section{REFERENCES}

1. Luksic I, Mulic R, Falconer R, Orban M, Sidhu S, Rudan I. Estimating Global and regional morbidity from acute bacterial meningitis in children: Assessment of the evidence. Croat Med J. 2013; 54(6):510-8.

2. Davis S, Feikin D, Johnson HL. The effect of Haemophilus influenza type $B$ and pneumococcal conjugate vaccines on childhood meningitis mortality: A systematic review. BMC Public Health. 2013; 13Suppl 3:s21.

3. Brouwer MC, Tunkel AR, Van de Beek D. Epidemiology, diagnosis, and antimicrobial treatment of acute bacterial meningitis. ClinMicrobiol Rev. 2010; 23(3):467-92.
4. Chinchankar N, Mane M, Bhave S, Bapat S, Bavdekar $A$, Pandit $A$, et al. Diagnosis and outcome of acute bacterial meningitis in early childhood. Indian Pediatr. 2002; 39(10):914-21.

5. Levy C, Varon E, Picard C, Bechet S, Martinot A, Bonacorsi $S$, et al. Trends of pneumococcal meningitis in children after introduction of the 13-valent peneumococcal conjugate vaccine in France. Pediatr Infect Dis J. 2014; 33(12):1216-21.

6. Kuti BP, Bello EO, Jegede TO, Olubosede O. Epidemiological, clinical and prognostic profile of childhood acute bacterial meningitis in a resource poor setting. J Neurosci Rural Pract. 2015; 6(4):549-57.

7. Naz S, Mushtaq A, Khan MZ, Bari A, Ahmad TM. Spectrum of acute complications and mortality in bacterial meningitis. Pak Pediatr 2012; 36(3):132-6.

8. Asghar RM, Ghani Z, Sharif M. Causative organisms, clinical course and complications of pyogenic meningitis in children. J Rawal Med Coll 2008; 12(2):88-91.

9. Kakar BA, Ahmed S, Kakar RM. Mortality and morbidity of 118 cases of acute pyogenic meningitis in paediatrics age group. Ann King Edward Med Uni 2006; 12(2):204-7.

10. Khowaja AR, Mohiudding $S$, Cohen AL, Khalid A, Mehmood U, Naqvi F, et al. Mortality and neurodevelopmental outcomes of acute bacterial meningitis in children aged $<5$ years in Pakistan. $J$ Pediatr. 2013; 163(1 Supp):S86-S91.

11. Mahon CR, Lehman DC, Manuselis G. Textbook of diagnostic microbiology. Philadelphia: Sauders Elsevier; 2007.

12. Dodge DR, Swartz MN. Bacterial Meningitis: A review of selected aspects: Special neurological problems, postmeningitic complications and clinical pathological correlation. N Eng J Med 1999; 272:95460.

13. CDC. Centers for diseases control and prevention (2011). Empidemiology of meningitis caused by neisseria meningitides, streptococcus pneumonia, and haemophilus influenza. Available at: http://www. cdc.gov/meningitis/lab-manual/chpt02-epi.html.

14. Loring KE. CNS infections. In: Tintinalli JE, Kelen GD, Stapczynski JS (Eds.). Emergency medicine: a comprehensive study guide. $6^{\text {th }}$ edition. McGraw-Hill, 2004, New York. Pp.1431-7.

15. Chang CJ, Chang WN, Huang LT, et al. Bacterial meningitis in infants: the epidemiology, clinical features, and prognostic factors. Brain Dev 2004; 26: 168-75. 
16. Fothergill LD, Wright J. Influenzal meningitis: The relation of age incidence to the bactericidal power of blood against the causal organism. J Immunol 1933; 24: 273-84.

17. Mclntyre PB, O'Brien KL, Greenwood B, van de Beek D. Effect of vaccines on bacterial meningitis worldwide. Lance 2012; 380:1703-11.

18. Azubuike J. Childhood bacterial meningitis in Tabuk Saudi Arabia. Annals of Saudi medicine 1990; 10:1458.
19. Louvois J, Huder BR, Harvy D. Infantile meningitis in England and Wales. Arch of dis in childhood 1991; 66:603-7.

20. Butler lan J, Johson RT. Central Nervous system infection. PaedClin of North America 1974; 21:649-69.

21. Akbani Y, Nizami SQ, Farooq S, et al. A study of pyogenic meningitis in children. Bacteriological aspect in relation to age. Pak Paed J 1998; 21-24.

22. Tajj MM, Iqbal SM, Arif M, Mazar K. Predictors of fatal outcome in 367 cases of pyogenic meningitis. Pak Paediatric J 1993; 17:115-22.

\begin{tabular}{|c|c|c|c|}
\hline \multicolumn{4}{|c|}{ AUTHORSHIP AND CONTRIBUTION DECLARATION } \\
\hline Sr. \# & Author-s Full Name & Contribution to the paper & Author $=\mathbf{s}$ Signature \\
\hline 2 & Muhammad Amin & $\begin{array}{l}\text { Methodology, Design, Data } \\
\text { analysis, Supervision. } \\
\text { Drafting, Data analysis, } \\
\text { Literature review, References. }\end{array}$ & \\
\hline 4 & Zunaira Javed & Data collection, Data analysis. & \\
\hline
\end{tabular}

